\title{
Reading Strategies and Reading Motivation among Secondary Level of Students in Sarawak
}

\author{
Mary Anne Dison, Parilah Mohd Shah
}

\begin{abstract}
This research was aimed to explore the reading strategies used in reading academic texts among secondary level of students, the motivations for reading among secondary level of students in learning English as well as to investigate whether is there a significant correlation between reading strategies and motivation for reading among secondary level of students. As students are facing various types of reading activities and reading materials in learning the language, reading strategies would be a great way of helping language learners to ease their understanding and facilitate them in learning the language better. Apart from that, motivation plays a vital role in stimulating the desire of language learners to learn. Therefore, this survey research design was employed by using the adapted questionnaire from Survey of Reading Strategies (Mokhtari and Ravi 2002) and Motivations for Reading Questionnaire (Wigfield and Guthrie 1997) as an instrument with the aim to identify reading strategies and reading motivation among secondary school students. This study involves convenience sampling of eighty-one $(n=81)$ secondary school students consisting of lower and upper secondary level which comes from different divisions in Sarawak. The result revealed that students are aware of reading strategies and they have the practice of using varieties of strategies when reading English materials. The study also discovered positive relationship between reading strategies used by secondary level of students and the motivation for reading among secondary level of students.
\end{abstract}

Index Terms - language learners, reading motivation, reading strategies, secondary level.

\section{INTRODUCTION}

Reading skill is known as the most important skill in acquiring the learning of English language. Second language learners are required to be proficient in reading in order to learn the language successfully. Apart from that, reading is one of the main activities in the language classroom as every students is involved in reading in many ways. Most successful language learners practice reading as their main bridge to knowledge gaining as they believed that it would help in learning other academic subjects and opens up the mind for better understanding. In the context of English language learning, reading strategies have been one of the main aspects in enhancing reading skills. As students are facing various types of reading activities and reading materials in learning the language, reading strategies would be a great way of helping language learners to ease their understanding and facilitate them in learning the language better. Apart from that, motivation plays a vital role in stimulating the desire of language learners to learn.

Mary Anne Dison, Universiti Kebangsaan Malaysia

Parilah Mohd Shah, Universiti Kebangsaan Malaysia
Therefore, this study is meant to discover two important aspects: (1) students' reading strategies in academic materials and (2) students' motivation for reading.The purpose of the study is to examine students' reading strategies and the reading motivations in learning English. This study also aims at investigating whether is there a significant correlation between reading strategies and motivation for reading among secondary level of students in learning English.

Reading skill is an essential skill that all students need for academic success, but there are students who were identified as having learning difficulties faced major problems with reading. Problems in reading such as inappropriate use of background knowledge Graham \&Bellert [12], lack of vocabulary knowledge Clemens \& Simmons [4], lack of reading fluency Graham \&Bellert [12] failure to distinguish between different text structures Gersten, Fuchs, Williams, \& Baker [8] and difficulty making inferences Hall, \& Barnes [15] which all have negative impact on students' reading ability to understand academic texts. Students will continue to struggle in their reading skills if these learning disabilities are not overcome in the early stage. Therefore, being able to successfully acquire reading skill would help students to advance greatly in their academic achievements and towards better readers.

Strategies can be defined as purposeful actions that learners choose and utilise to achieve goals or objectives Anderson [1]. Finding out which reading technique is being used and which is effective in enhancing or helping a learner to understand or memorize certain reading materials such as instructional reading materials, can be of great help in deciding which techniques should be used in the syllabus when teaching reading skill. The importance of awareness of reading strategies among students should be emphasized so as to support their knowledge in the tasks assigned. Students would be more responsive and able to construct meaning from the text once they have a good practice of reading strategies and being aware of the suitable strategies to be applied in their reading skill.While academic materials can be challenging to some struggling students, teachers play an important role to provide emphasis to students on how to understand and acquire the reading strategies in order for them to learn the academic materials better.According to Singhal [27], reading strategies imply how learners respond to given tasks, assist them in understanding as well as a guide to comprehend. Apart from that, learners must be aware of their knowledge process in developing reading skill by carefully selecting appropriate strategies to assist them in getting meaning of their reading materials. Whereas,students who are lacking in acquiring reading strategies tend to spend extra time to understand each word rather than to construct 
meaning from the text. Consequently, these students would face challenges in dealing with academic materials such as textbooks and the possibility of not possessing the necessary reading strategies are high which would eventually affect their reading skills in the future Mokhtari\&Sheorey [22].

\section{LITERATURE REVIEW}

\section{A. Metacognitive Reading Strategies}

The phrase metacognition primarily suggests to thinking about one's thinking. Karbalaei [18] defined metacognition as the knowledge and control that one has towards cognitive processes. According to Flavell [7], metacognition involves the process about an individual's knowledge towards thinking processes, active observation and the control of cognitive processing activities. According to Auerbach\& Paxton [2] metacognitive awareness refers to the knowledge about suitable actions that one takes to achieve a goal. In relation to reading, metacognitive awareness and control is common to be discussed. Essentially, each individual develop awareness of own comprehension processing and eventually learn the strategies that help to increase comprehension and ways to execute these strategies effectively. As second language learners apply metacognitive awareness in the process of reading, it can be defined as readers' cognition knowledge towards the process of reading and the ways of control that readers use to observe and enhance understanding and comprehension Sheorey\&Mokhtari [26]. Metacognition is important for learners to be constantly aware about their learning and being able to recognise when to apply the suitable strategies in their learning and continuously practice in using them. This would help learners to give direction and opportunity to consciously keep track of their learning progress.

According to Flavell [7], reading is a cognitive activity that happens when there is an existence of interaction between reader, text and the context in which reading occurs. Besides, as language learners undergo the process of reading, they need to apply metacognitive knowledge and make use of the strategies in order to achieve the task of comprehending a text successfully. There are a few contributing factors towards readers' metacognitive knowledge about reading when they face specific reading task. This includes learners' previous learning experiences, learners' beliefs and practice in learning and learners' language proficiency. Metacognitive awareness of the readers in relation to reading includes the awareness of various reading strategies and the cognitive processes that involves in reading which is highly related by metacognitive awareness of reading strategies. Therefore, it is the combination of deliberate awareness of reading, essential reading processes and the actual application of reading strategies that differs competent from less competent readers. In order for learners to develop better into active and constructive responsive readers, teachers play an important role to enhance their understanding of readers' metacognitive knowledge.

\section{B. Reading Motivation}

Motivation often referred to the beliefs, values and goals which drive an individual's action towards achieving a target. In a research by Bojović and Antonijević [3] which studied on the characteristics of students' motivation to learn in primary school has resulted that students believed they can achieve their goals by self-efficacy. In this context, self-efficacy reflects on the children's beliefs towards their ability and evaluations of their capabilities in different areas of learning. The outcomes of the research showed the importance of social goals to primary school students and they have high level of self-perception of competences.

According to Wigfield et al [29], reading motivation is strongly related to reading outcomes in terms of students' comprehension in reading, using effective strategies in enhancing reading skills and reading performance which can be assessed through grades. McGeown [20] explained that there are two main theories which are commonly discussed to describe the reasons behind why second language learners are motivated to read are the intrinsic and extrinsic theory of reading motivation. The differences between intrinsic and extrinsic theory are the internal and external goals to explain why learners read. For instance, if a learner decides to read because it is interesting thing to do, this is considered as an internal reason or known as intrinsic motivation. Whereas, when a learner chooses to read in order to achieve recognition, acquire better grades and get praises from their parents and teachers, then this is considered as an external reason or known as extrinsic motivation. Learners' curiosity, involvement and preference for challenge are some of the characteristics of intrinsic reading motivation. When learners have the desire to gain more knowledge or new things through reading shows that they have the curiosity to learn. Learners' involvement can be seen in their level of engagement when they read and the learners' desire to work and comprehend difficult reading materials shows the preference for challenge in reading. Extrinsic reading motivation is perceived as competition, recognition, grades, compliance and social aspects in learners' reading activity. When readers have the desire to perform well compared to others in reading, it shows that they develop the sense of competition in them. Recognition in reading can be perceived as the learners need to be recognised for their reading achievements. A learners' need to achieve good achievements or marks in reading is also perceived as extrinsic reading motivation. Reading compliance refers to the learners' fulfilment to the external or outer requirement to read while social aspect in the extrinsic reading motivation refers to the learners' engagement in social interactions which involve reading activity.

Guthrie and Wigfield [13] stated that reading motivation plays a vital role in learners' beliefs towards their positive or negative thoughts about reading. For instance, learners' who read by their willingness and the desire to improve their understanding are considered as extremely motivated readers. They are the types of readers that believed reading to be an important aspect in their learning or daily activities. They are also considered as one who are capable to receive challenges in the reading process and have high tendency to develop into effective readers. Apart from that, reading motivation is a person's drive, idea, desire and interest associated to the consequences of reading. 
Pachtman and Wilson [23] emphasized the importance of motivating learners to read by providing them ample choices to choose their most preferred reading materials. By doing so, it would allow readers to read more when they are allowed to have their choice of reading materials because they have to learn that reading is an enjoyable activity. As stated by Hairul, Ahmadi and Pourhosein [14], reading motivation is the significant extent of motivation that learners possess to ponder their positive or negative thoughts towards reading. For example, learners who are able to employ strategies to support their comprehension when reading texts are perceived as motivated readers and they see reading as a vital factor in their daily activities which eventually would help them to develop to be a successful readers.

According to Hairul, Ahmadi and Pourhosein [14], reading motivation and reading comprehension are associated with one another in a way that reading motivation influences every aspects of reading comprehension strategies in various circumstances. They believed that learners' motivation has great effect on their reading which means that learners who have greater reading motivation are presumed to read extra in broader range. They also emphasised that reading motivation is one of the most significant factors which support learners to read more and has essential impact on learners in comprehending reading materials. Thus, teachers should be aware of the importance of motivation in reading among learners and how it would increase reading comprehension so they could be a support in students' learning activity.

\section{Reading skill}

The ability to understand and comprehend a reading material is essential in the process of learning for language learners. In secondary education, learning English as a second language demands teachers to understand reading strategies and teach the students how to apply it in their learning which would support students' reading skill and comprehension. As mentioned by Hulme and Snowling [17], acquisition of reading is the main goal of early education and the condition of not being able to read would cause a serious consequences. As students move forwards in their process of learning, they are expected to read and write with improved skill and competency.

Wigfield et al [29] stated that the increase demand in reading materials for childhood and adolescence ought the readers to be fluent in the process of comprehending words, building up of vocabulary, and the ability to learn and apply strategies to understand a text. The fluency of these skills are greatly dependant on the early childhood awareness and letter knowledge which are commonly known as the vital components of reading words and sentences. The importance of developing reading skill is greatly emphasised because it impacted greatly towards students' reading achievement as they progress through school. Students or language learners need to have the responsibility in mastering the necessary skills and strategies by committing time and effort to learn them. Therefore, language learners must be encouraged and motivated to learn and then use these skills and strategies effectively.

\section{Related studies}

A research conducted by Eletaa\&Abdalla [6] found that reading strategies are helpful in enhancing reading skills among secondary school students. The study recommended students to read more English texts and apply the reading techniques that were taught by their teachers. The research also suggested that teachers are ought to encourage students to utilise appropriate reading strategies to be an effective reader and proper training for students on how to use reading strategies in reading academic materials should be practiced by teachers.

In a case study by Ejlal (2017), the researcher investigated the effects of reading ability on writing performance among Sudan University students. The results of the study proved that reading ability has positive effects on the students writing performance. The researcher pointed out that students with good competency in reading skill would affect greatly towards their writing performance. Hence, it can be concluded that reading ability is indeed a core skill in developing other language skills such as writing.

In a research conducted by Daff et al (2013), the main findings were reading strategies has an important role in helping to enhance reading skills, motivation and attitudes among students. In this context, teacher's role is to help students develop their reading strategies in order for them to acquire reading skill and develop into an effective reader. Hassan [16] concluded in his case study that students are more motivated in using reading strategies when they are provided properly with teacher's guidance. The result in this study explored using reading strategies would facilitate students in comprehending academic text. Whereas a study by Küçükoğlu [19] investigated whether reading strategies would help the students in reading comprehension which resulted that there was a great improvement among students in terms of their understanding towards reading strategies and reading comprehension when the teacher has taught them knowledge about reading strategies and how to use it.

A study was conducted by Phakiti [24] which investigated the relationship between reading strategy use and reading test performance among Thai university students that enrolled English course. These students were required to take a reading comprehension test and answered a questionnaire regarding their usage of cognitive and metacognitive reading strategies while they take the test. The study employed eight students which consists of four proficient learners and four less proficient learners to be interviewed. The result showed that cognitive and metacognitive strategies employed by students could prove that differences in reading performance test. Thus, there is an existence of positive relationship between the use of cognitive and metacognitive strategies with students' reading test performance. This study also proved that students who are more proficient and successful in their performance have higher metacognitive strategy use compared to the less successful students.

A research carried out by Dornyei [5] and Grabe [11] had discovered the existence of strong impact of motivation on reading comprehension proficiency. These researchers also revealed that motivation is highly associated with reading comprehension and could facilitate in learners reading skill. In a research by Schutte and Malouff [25], they showed that learners' motivation has effect on their reading skill. Learners with greater motivation tend to read broader and wider. Gottfried [9] stated in a study that reading comprehension has 
a positive relationship towards intrinsic motivation for reading. Thus, it can be concluded that learners' reading performance or reading skill are greatly impacted by learners' internal drive of desire towards reading. Learners that have high intrinsic motivation perform well on different reading tasks Gottfried, et al [10].

\section{METHODOLOGY}

This research design attempted at employing a survey design by using questionnaire as an instrument with the aim to identify reading strategies and reading motivation among secondary school students. This study involves convenience sampling of eighty-one $(n=81)$ secondary school students consisting of lower and upper secondary level which comes from different divisions in Sarawak. The respondents are located in Limbang, Bintulu, Samarahan, Kuching, Miri, Serian, Betong and Sibu. There were 23respondents from Limbang, 16 from Bintulu, 13 from Samarahan, 12 from Kuching, 10 from Miri, 4 from Serian 2 from Betong and 1 from Sibu. There were 33 males (41\%) and 48 females (59\%) who participated in this study. The study employed convenience sampling because the researcher considered on the availability of the respondents. The respondents in this study are readily available, reachable and willing to participate in this study. This study was conducted using two different types of questionnaire to collect the information regarding reading strategies and reading motivation. The Survey of Reading Strategies Mokhtariand Ravi [21]was adapted and administered to investigate the reading strategies that were being practiced by secondary level of students while the Motivations for Reading Questionnaire Wigfield and Guthrie [28] was used in this study aiming to explore students' reading motivation. The researcher selected the questionnaire as an instrument to this study because of its suitability and appropriateness for the research context. Initially, there were thirty (30) items in the Survey of Reading Strategies Mokhtari and Ravi [21] instrument while fifty-three (53) items in the Motivations for Reading Questionnaire Wigfield and Guthrie [28]instrument. The researcher had to analyse both of the questionnaire and choose the appropriate items to be used in this study. The questionnaire was later tailored to fit the purpose of this study in discovering the reading strategies and reading motivation among secondary level of students.

The Survey of Reading Strategies Mokhtari and Ravi [21]questionnaire consists of three categories of reading strategies which include the Global Reading Strategies, Problem Reading Strategies and Support Reading Strategies. There are five items to represent for each categories of reading strategies which made a total of fifteen (15) items to investigate the reading strategies employed by secondary level of students. These items are measured in a likert scale of 1-5 (1-Never, 2-Occcasionally, 3-Sometimes, 4-Usually, 5-Always). The respondents needed to select only one answer to each item which are closely related to their reading strategy.

As for the Motivations for Reading Questionnaire Wigfield and Guthrie [28] consists of fifteen items (15) that measure aspects of reading motivation. These items consist of four point likert scale ranging from strongly disagree (1), disagree (2), agree (3) and strongly agree (4). Each respondents were required to select only one answer from the provided choices that are strongly related to their motivations for reading.

\section{FINDINGS}

The result of the study will be explained according to the research questions mentioned:

Research Question 1: What are the reading strategies used in reading academic texts among secondary level of students? There were 15 items in this study used to measure reading strategies employed by secondary level of students in reading academic texts. The types of reading strategies are categorised into three main groups namely Global Reading Strategies (GLOB) - 5 items, Problem-Solving Strategies (PROB) - 5 items and Support Strategies (SUP) - 5 items. The five items measuring Global Reading Strategies (GLOB) are the following: I read for a purpose; I do prior thinking to help me understand what I read; I view the text overall to see what it's all about before I read it; I decide whether the content of the text suits to the purpose of my reading; When reading, I translate English to Malay. A majority of students practice 'I decide whether the content of the text suits to the purpose of my reading' as their most preferred strategy which revealed the highest percentage $(56.8 \%)$ a total number of 46 students compared to other strategies. A number of 43 students $(53.1 \%)$ showed that they view the text overall to see what it's all about before reading while 42 students (51.9\%) read for a purpose. There were 39 students $(48.2 \%)$ do prior thinking to help them understand what they read and the least number representing 13 students $(17.2 \%)$ showed that they use translation method while reading. The result reflected that the highest percentage $(56.8 \%)$ secondary level of students usually and always decide whether the content of the text suits to the purpose of their reading. It shows that students are independent learners as they are able to do decision for their reading activity and choose the suitable reading materials which suit to their aim of reading.

The five items measuring Problem-Solving Strategies (PROB) are the following: I read slowly and carefully to ensure I understand what I am reading; I try to get back on track when I lose concentration; I change my reading speed according to what I am reading; When text becomes difficult, I pay closer attention to what I am reading; I stop from time to time and think about what I am reading. Item 'I try to get back on track when I lose concentration' shows the highest percentage $(66.6 \%)$ among the other items for PROB reading strategies. This indicates that students have the awareness of strategy to solve problems while they are reading. For the two items in this strategy, 'I read slowly and carefully to ensure I understand what I am reading' and item 'When text becomes difficult, I pay closer attention to what I am reading' shows the same amount of students who applied this strategy when they face problem in their reading activity which responses are from 49 students that made up a total percentage of $60.5 \%$ for both items. A total number of 48 students (59.3\%) applied the strategy of 'I change my reading speed according to what I am reading'. As for item 'I stop from time to time and think about what I am reading', there are only 28 students (35.8\%) who used this strategy in their reading task.

The five items measuring Support Strategies (SUP) are the following: I take notes to have better understanding while I read; I read aloud to help me understand when text becomes difficult; I underline, circle or highlight information in the 
text to help me remember it; I use dictionary to help me understand what I read; I go back and forth in the text to find relationships among ideas in it. A majority of students picked item 'I underline, circle or highlight information in the text to help me remember it' as their preferred strategy in reading academic materials. This item has the highest number of respondents which is 45 students $(55.6 \%)$ that frequently applied various techniques such as underlining, circle and highlighting as a way of remembering, understanding and comprehending a text. This strategy is chosen mostly by the secondary school students because it could support in their reading activity and help in their information processing and memory retention. This technique is also one way for students to note important information as they read. As for item 'I go back and forth in the text to find relationships among ideas in it', 38 students (47\%) always used this strategy in their reading task. Some students preferred going back and forth in the text to support their reading comprehension because they wanted to learn the connection of ideas and thoughts found in the text. The item 'I use dictionary to help me understand what I read' shows 31 students $(39.5 \%)$ used this strategy often times while reading. This technique helps students in referring to reliable source of information such as the dictionary to look up for meaning of words and the grammar usage. Whereas for strategy 'I read aloud to help me understand when text becomes difficult' has 31 respondents $(38.3 \%)$ who always used this strategy while reading. Therefore, only a total of 25 students $(32 \%)$ picked item 'I take notes to have better understanding while I read' as their strategy in reading activity.

Research Question 2: What are the motivations for reading among secondary level of students in learning English?

There were 15 items used in this research to measure the reading motivation among secondary level of students in learning English. The 15 items are, I am a good reader, I like hard and challenging books, I don't care how hard it is to read if a book is interesting, I learn difficult things by reading, I enjoy a lengthy story book, It is very important to me to be a good reader, I like being the best at reading, I like being the only one who knows an answer in something we read, My parents always praise me for being good at reading, I like when my teacher say I read well, I read to get good grades/results in school, School results/grades are a good way to see how well you are doing in reading, I always go to the library with my family, I talk to my friends about what I am reading and I always try to finish my reading on time. These 15 items are categorised into eight constructs namely Reading Efficacy (1 item; I am a good reader), Reading Challenge ( 3 items; I like hard and challenging books, I don't care how hard it is to read if a book is interesting, I learn difficult things by reading, ), Reading Involvement (1 item; I enjoy a lengthy story book), Importance of Reading (1 item; It is very important to me to be a good reader), Competition in Reading ( 2 items; I like being the best at reading, I like being the only one who knows an answer in something we read), Recognition for Reading ( 2 items; My parents always praise me for being good at reading, I like when my teacher say I read well), Reading for Grades (2 items; I read to get good grades/results in school, School results/grades are a good way to see how well you are doing in reading), Social reasons for reading (2 items; I always go to the library with my family,
I talk to my friends about what I am reading) and Compliance (1 item; I always try to finish my reading on time).

Result shows that $29.6 \%$ of students chose 'Strongly Agree', $32.1 \%$ of students chose 'Agree', $35.8 \%$ of students chose 'Disagree' and $2.5 \%$ of students chose 'Strongly Disagree' for item 'I am a good reader'. This result shows a majority of students indicate that they have self-efficacy and those who believe that they are able to read well are prone to read frequently. As for item 'I like hard and challenging books', $17.3 \%$ of students chose 'Strongly Agree', $40.7 \%$ of students chose 'Agree', $35.8 \%$ of students chose 'Disagree' and 6.2\% of students chose 'Strongly Disagree'. For this item, it clearly shows that most of the students enjoy reading hard and challenging books. Item 'I don't care how hard it is to read if a book is interesting' shows high percentage of students which is $53.1 \%$ who chose 'Strongly agree', $24.7 \%$ of students chose 'Agree', $19.8 \%$ of students chose 'Disagree' and 2.5\% of students chose 'Strongly disagree'. This item proves that the students are more motivated in reading if the book is interesting despite how hard it is. A total percentage of $40.7 \%$ students chose 'Strongly agree', $27.2 \%$ of students chose ' Agree', 29.6\% of students chose 'Disagree' and 2.5\% of students chose 'Strongly disagree' for item 'I learn difficult things by reading' which conclude that a majority of students have the practice of reading when encountering difficult things or tasks. As for reading involvement, item 'I enjoy a lengthy story book' has $17.3 \%$ of students selected 'Strongly agree', $40.7 \%$ of students selected 'Agree', $29.6 \%$ of students selected 'Disagree' and $12.3 \%$ of students selected 'Strongly disagree'. From the percentage count, it can be concluded that most students love reading long story book. For item 'It is very important to me to be a good reader' aims to look at students' awareness about the importance of reading. The result shows that $49.4 \%$ of students picked 'Strongly agree', $30.9 \%$ of students picked 'Agree', $16.0 \%$ of students picked 'Disagree' and $3.7 \%$ of students picked 'Strongly disagree' for item 'It is very important to me to be a good reader'. For item 'I like being the best at reading', $48.1 \%$ of students opted 'Strongly agree' while $29.6 \%$ of the students which opted 'Agree', 16.0\% opted 'Disagree' and 6.2\% opted 'Strong disagree'. Item 'I like being the only one who knows an answer in something we read' shows a percentage count of $34.6 \%$ that opted for 'Strongly agree', 30.9\% opted for 'Agree' while $25.9 \%$ opted 'Disagree' and $8.6 \%$ opted 'Strongly disagree'. This result proves that students have the sense of competitiveness in reading because a majority of them have the desire to be the best at reading and they are keen in knowing the answer for information that they read. As for item 'My parents always praise me for being good at reading', a percentage count of $27.2 \%$ chose 'Strongly agree', 34.6\% chose 'Agree', 29.6\% chose 'Disagree' while 8.6\% chose 'Strongly Disagree' whereas item 'I like when my teacher say I read well' shows $58.0 \%$ chose 'Strongly Agree', $23.5 \%$ chose 'Agree', $14.8 \%$ chose 'Disagree' and 3.7\% chose 'Strongly Disagree'. From these two items, it can be deduced that secondary level of students are more motivated to read when their parents and teachers praise them for reading well. It shows that recognition for reading is greatly important for students to be motivated in reading. The item 'I 
read to get good grades/results in school' shows $45.7 \%$ selected 'Strongly agree', 33.3\% selected 'Agree', 14.8\% selected 'Disagree' and 6.2\% selected 'Strongly disagree' while item 'School results/grades are a good way to see how well you are doing in reading' shows 32.1\% selected 'Strongly agree', 38.3\% selected 'Agree', $19.8 \%$ selected 'Disagree' and 9.9\% selected 'Strongly disagree'. The result shows that most students of secondary level agreed on school grades indicate how they progress in reading and they practice reading to obtain achieve good result in school assessment. As for social reasons for reading, two items are used in this study to measure students reading motivation namely, 'I always go to the library with my family' and 'I talk to my friends about what I am reading'. Item 'I always go to the library with my family' indicate that the highest percentage count is $39.5 \%$ chose 'Strongly Disagree', 33.3\% chose 'Disagree', $14.8 \%$ chose 'Agree' and only $12.3 \%$ chose 'Strongly Agree'. From this result, a majority of students do not prefer going to the library. Only a small amount of students still go to the library with their family. As for item 'I talk to my friends about what I am reading', the highest percentage count of 33.3\% selected 'Agree', 25.9\% selected 'Strongly agree', 27.2\% selected 'Disagree' and 13.6\% selected 'Strongly disagree'. This implies that students of secondary level have social reasons for reading. As they read, they share about it to their friends. Lastly, for item 'I always try to finish my reading on time' shows $23.9 \%$ selected 'Strongly agree', 30.9\% selected 'Agree', 34.6\% selected 'Disagree' and $8.6 \%$ selected 'Strongly disagree'. This proves that most students comply in the task given to them by trying to complete their reading on time.

Research Question 3: Is there a significant correlation between reading strategies and motivation for reading among secondary level of students?

As for the third research question, the Pearson product-moment correlation coefficient test was carried out to investigate whether is there a significant correlation between reading strategies and motivation for reading among secondary level of students. The result of Pearson's correlation test shown that 0.737 which revealed to the existence of correlation between reading strategies and motivation for reading among secondary level of students. According to Laerd Statistics (2018), when coefficient, $r$ is between .5 to 1.0 the strength of association is large. Therefore, the more reading strategies that students used, the higher the reading motivation among secondary level of students.

\section{DISCUSSION}

This study gives a general view of the use of reading strategies among secondary level of students by investigating their usage of reading strategies in reading academic text or English materials. In addition, this study also provides insights on motivations for reading among secondary level of students in learning English by exploring their motivations for reading. The results revealed that students are aware of reading strategies and they have the practice of using varieties of strategies when reading English materials. Among the three groups of reading strategies, it can be seen that students of secondary level are likely to apply Problem Reading Strategies followed by Global Reading Strategies and Support Reading Strategies. Among the five items measuring for Problem Reading Strategies, a high percentage of students preferred getting back on track when they lose concentration which shows that they are mindful of wanting to know better by reading the materials all over again when losing their attention. It reflected that students of secondary level have the persistence to identify their problem in understanding the reading material and try to seek answer to solve them. As for Global Reading Strategies, the result reflected that a high percentage of secondary level students practice the strategy of deciding their choice of reading materials to suit to the reading purpose. It shows that students are independent learners as they are able to do decision for their reading activity and choose the suitable reading materials which suit to their aim of reading.

The Support Reading Strategies show that students of secondary level frequently practice various techniques such as underlining, circle and highlighting as a way of remembering, understanding and comprehending a text. This strategy is chosen mostly by the secondary school students because it could support in their reading activity and help in their information processing and memory retention. This technique is also one way for students to note important information as they read.

This study also revealed the motivations for reading among secondary level of students are the highest for item 'I like when my teacher say I read well' as there are $58.0 \%$ strongly agree to this statement. . The result reflected that the aspect of motivation for reading among students of secondary level is recognition for reading. The result revealed that students like to receive praises from their teachers when they read well. This shows that students are highly motivated to read when they are complimented by their teachers for reading well. In addition, $53.1 \%$ strongly agree that they like hard and challenging books. This proves that students are highly motivated to read despite the reading materials are difficult and challenging to them. Therefore, it can be concluded that students of secondary level have the sense of challenge in reading which reflected a positive attributes in them towards the practice of reading. There are $49.4 \%$ of students in the secondary level strongly agree that being a good reader is important to them. This shows that they are aware about the importance of reading and being a good reader keeps their motivation high. In contrary, only $12.3 \%$ of students strongly agree that they always go to the library with their family which simply means that only a small amount of students still visit the library with their family while the rest do not prefer to go to the library. This result indicates that social reasons are not the most important aspect in motivation for reading among secondary level of students. Overall, this study discovered that secondary level of students have their own choice and preferences when it comes to utilising reading strategies in comprehending reading materials or other academic texts. The outcome of this study also shows that there are some reading strategies that students never use or only used occasionally and sometimes. This could be due to the reason that students have never been exposed to this 
strategy or they do not know how to apply it in their reading activity.

Whereas, aspects in motivation for reading shows that students have different choice of motivations for reading. Most of the students are motivated to read when the reading materials are hard and challenging which shows that students have high reading challenge in them. This study also revealed that a majority of students love getting praises from their teacher when they do well in reading which leads them to being more motivated in reading. The result reflected that the aspect of motivation for reading among students of secondary level is important as it shows recognition for reading. They also realise the importance of being a good reader which is another aspect that leads towards high motivation for reading. The correlation test between reading strategies used by secondary level of students and motivations for reading shows a large association which indicates the existence of relationship between the two variables. Thus, the more reading strategies used by secondary level of students, the higher the motivation for reading among secondary level of students.

\section{CONCLUSION}

This study concludes that students should develop reading culture as their main source of information and knowledge gaining as it could widen students' views and opinions. Eventually, when students practice the culture of reading, they could utilise various reading strategies in comprehending academic materials or English texts. As students learn to apply various reading strategies, they are highly motivated towards reading which leads towards positive outcome in the learning process. Thus, it is suggested for the teachers to consider teaching reading strategies among students as it would ease them in better understanding while reading. Students should also provide positive response towards learning reading strategies so they could utilise them more effectively.

\section{REFERENCES}

[1] Anderson, N.J. (1999). Exploring Second Language Reading: Issues and Strategies, Heinle\&Heinle Publishers.

[2] Auerbach, E. R., \& Paxton, D. (1997). "It's not the English thing": Bringing reading research into the ESL classroom. TESOL Quarterly, 31, 237-261.

[3] Bojovic, I., \&Antonijevic, R. (2017). Students' Motivation to Learn in Primary School. Open Journal for Psychological Research, 1, 11 20. https://doi.org/10.32591/coas.ojpr.0101.02011b

[4] Clemens, N., \& Simmons, D. (2014). Examining the role of vocabulary knowledge in struggling comprehenders. Paper presented at the meeting of The Council for Exceptional Children, Philadelphia, PA.

[5] Dornyei, Z. (2006). Individual Differences in Second Language Acquisition. AILA Review, 19(1), 42-68.

[6] Eletaa, N. A., \& Abdalla, A. Y. (2016). Investigating the Effects of Using Reading Strategies on Improving Secondary School. Journal of Humanities, 171-184.

[7] Flavell, J. H. (1979). Metacognition and cognitive monitoring: A new era of cognitive-developmental inquiry. American Psychologist, 34(10), 906-911. http://dx.doi.org/10.1037/0003-066x.34.10.906

[8] Gersten, R, Fuchs, L., Williams, J., \& Baker, S. (2001). Teaching reading comprehension strategies to students with learning disabilities: A review of research. Review of Educational Research, 71(2), 279-320. doi: 10.3102/00346543071002279

[9] Gottfried, A. E. (1990). Academic Intrinsic Motivation in Young Elementary School Children. Journal of Educational Psychology, 82(3), 525-538. http://dx.doi.org/10.1037/0022-0663.82.3.525
[10] Gottfried, A. W., Cook, C. R., Gottfried, A. E., \& Morris, P. E. (2005) Educational Characteristics of Adolescents with Gifted Academic Intrinsic Motivation: A Longitudinal Investigation from School Entry through Early Adulthood. Gifted Child Quarterly, 49(2), 172-186. doi:10.1177/001698620504900206

[11] Grabe, W. (2009). Reading in a Second Language; Moving from Theory to Practice. New York: Cambridge University Press.

[12] Graham, L., \&Bellert, A. (2005). Reading comprehension difficulties experienced by students with learning disabilities. Australian Journal of Learning Disabilities, $10 \quad$ (2), 71-78. doi:10.1080/19404150509546791

[13] Guthrie, J. T., \&Wigfield, A. (2000). Engagement and Motivation in Reading. In M. L. Kamil, P. B. Mosenthal, P.D. Pearson, and R. Barr (Eds.), Handbook of Reading Research. (Vol. III, pp. 403-22). Mahwah, NJ: Lawrence Erlbaum Associates.

[14] Hairul, N. I., Ahmadi, M. R., \&PourhoseinGilakjani, A. (2012). The Role of Reciprocal Teaching Strategy as an Important Factor of Improving Reading Motivation. Elixir Edu. Tec, 53(3) 11836-11841.

[15] Hall, C., \& Barnes, M. (2017). Inference instruction to support reading comprehension for elementary students with learning disabilities. Intervention in School and Clinic, 52(5), 279-286. doi:10.1177/1053451216676799

[16] Hassan, M. (2018). Sudan University of Science and Technology Repository.

[17] Hulme, C., \&Snowling, M. J. (2015). Learning to Read: What We Know and What We Need to Understand Better. Child development perspectives, 7(1), 1-5. https://doi.org/10.1111/cdep.12005

[18] Karbalaei, A. (2011). Metacognition and Reading Comprehension. $\begin{array}{lll}\text { Íkala }, 16(2), & \text { R-14. } & \text { Retrieved }\end{array}$ https://revistas.udea.edu.co/index.php/ikala/article/view/9913

[19] Küçükoğlu, H. (2012). Improving Reading Skills Through Effective Reading Strategies. Procedia - Social and Behavioral Sciences, 709-714.

[20] McGeown, S. P. 2013. Reading Motivation and Engagement in the Primary School Classroom: Theory, Research and Practice. Leicester: United Kingdom Literacy Minibook Series.

[21] Mokhtari , K. \&Sheorey, R. (2002). Measuring ESL Students' Awareness of Reading Strategies. Retrieved April 2, 2011 from: http://nelson.myfastmail.com/Intensive\%20Reading\%20\%20Content \%20Based/Student\%20 se/MeasuringESL-stratgy.pdf

[22] Mokhtari , K. \&Sheorey, R. (2002). Measuring ESL Students Awareness of Reading Strategies. Retrieved April 2, 2011 from: http://nelson.myfastmail.com/Intensive\%20Reading\%20\%20Content $\%$ 20Based/Student\%20use/MeasuringESL-stratgy.pdf

[23] Pachtman, A. B., \& Wilson, K. A. (2006). What Do the Kids Think? The Reading Teacher, 59(7), 680-684.

[24] Phakiti, A. (2003). A Closer Look at the Relationship of Cognitive and Metacognitive Strategy Use to EFL Reading Achievement Test Performance. Language Testing. 20(1), 26-56.

[25] Schutte, N. S., \&Malouff, J. M. (2007). Dimensions of Reading Motivation: Development of an Adult Reading Motivation Scale. Reading Psychology, 28(5), 469-489.

[26] Sheorey, R., \&Mokhtari, K. (2001). Differences in the metacognitive awareness of reading strategies among native and non-native readers. System, 29, 431-449.

[27] Singhal, M. (2001). Reading Proficiency, Reading Strategies, Metacognitive Awareness and L2 Readers. Retrieved April 2, 2011 from http://www.readingmatrix.com/articles/singhal/

[28] Wigfield, A., \& Guthrie, J. (1997). Relations of children's motivation for reading to the amount and breadth of their reading. Journal of Educational Psychology, 89(3), 420-432.

[29] Wigfield, A., Gladstone, J., \&Turci, L. (2016). Beyond Cognition: Reading Motivation and Reading Comprehension. Child development perspectives, 10(3), 190-195. https://doi.org/10.1111/cdep.12184 